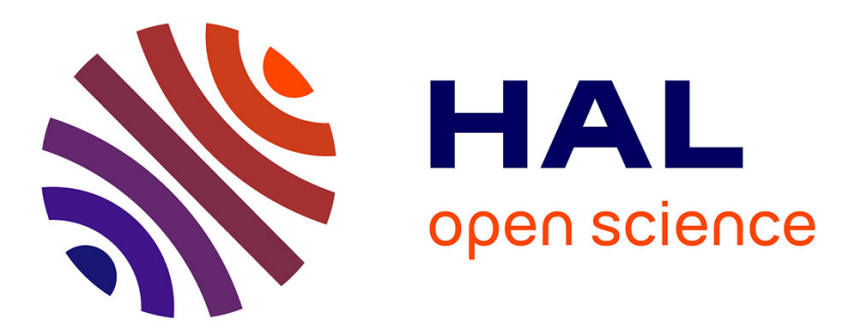

\title{
Improvement of engineering performance of magnesium alloys through rapid solidification technique
}

\author{
D. Daloz, G. Michot
}

\section{To cite this version:}

D. Daloz, G. Michot. Improvement of engineering performance of magnesium alloys through rapid solidification technique. Journal de Physique IV Proceedings, 1993, 03 (C7), pp.C7-537-C7-540. 10.1051/jp4:1993787 . jpa-00252207

\section{HAL Id: jpa-00252207 https://hal.science/jpa-00252207}

Submitted on 1 Jan 1993

HAL is a multi-disciplinary open access archive for the deposit and dissemination of scientific research documents, whether they are published or not. The documents may come from teaching and research institutions in France or abroad, or from public or private research centers.
L'archive ouverte pluridisciplinaire HAL, est destinée au dépôt et à la diffusion de documents scientifiques de niveau recherche, publiés ou non, émanant des établissements d'enseignement et de recherche français ou étrangers, des laboratoires publics ou privés. 


\title{
Improvement of engineering performance of magnesium alloys through rapid solidification technique
}

\author{
D. DALOZ and G. MICHOT
}

Laboratoire de Métallurgie Physique \& Science des Matériaux, URA 155 du CNRS, Ecole des Mines de Nancy, Parc de Saurupt, 54042 Nancy cedex, France

\begin{abstract}
Magnesium-Aluminium-Zinc powders are produced by centrifugal atomization. The microstructural refinement achieved by rapid solidification can be maintained throughout the extrusion process. The consolidated Mg-xAl-yZn alloys ( $\mathrm{x}=8,15$ or $20, \mathrm{y}=1$ or 3 at $\%$ ) exhibit enhanced mechanical properties and corrosion behaviour as well. Structural hardening is expected from the $\mathrm{Mg}$ - $\mathrm{Zn}$ system (GP zones)[1] and from decomposition of the supersaturated $\mathrm{Mg}$-Al solid solution $\left(\mathrm{Mg}_{17} \mathrm{Al}_{12}\right.$ precipitation). Furthermore a higher isotropy is expected from the reduction in grain size. The tensile strength of the alloy, larger than $400 \mathrm{MPa}$, is an increasing function of the aluminium content which must be kept below $\approx 15$ at $\%$ in order to achieve a reasonable ductility. The benefits brought by rapid solidification to corrosion resistance are evident on weight loss tests in 3\% salt water. A complete electrochemical study of corrosion rate and mechanism is on the way to confirm this first observation. This work gives additional informations to previous results obtained on ribbons with a lower content in aluminium [2].
\end{abstract}

\section{INTRODUCTION}

In order to improve the structural efficiency of aerospace systems, light weight metals are subjected to a larger attention from the aerospace industries. With a density range from 1.5 to $1.9 \mathrm{~g}^{-3} \mathrm{~cm}^{-3}$ (approximately the two-third of aluminium alloys), magnesium alloys are the best candidates. In fact, the poor corrosion resistance, strength and creep resistance of these alloys restrict their use. The low solubility of additional elements at room temperature is often responsible for these low properties

These restrictions, imposed by cast ingot metallurgy, can be overcome by rapid solidification through which higher supersaturated solution, smaller grain size, finer distribution of intermetallic and more uniform microstructure can be achieved. Starting from the alloy AZ-91 we increase the concentration of $\mathrm{Al}$ from 8 to 20 at $\%$ and $\mathrm{Zn}$ from 1 to 3 at \%. This article shows the resulting improvement of mechanical properties due to rapid solidification method

\section{EXPERIMENTAL}

Rapid solidification requires small size products to allow rapid removal of heat, i.e. ribbons or powder. The latter possibility was developed at the laboratory through an improvement of the original centrifugal atomization process [3] : the liquid metal poured onto the centre of a cup where it spreads and then divides into droplets on its edge. Solidification takes place during the droplet flight toward the chamber wall : cooling rates up to $10^{4} \mathrm{C} \mathrm{s}^{-1}$ are achieved in the helium atmosphere. After sieving of the powder, the diameter range $50-100 \mu \mathrm{m}$ is put aside for consolidation. Degassing is achieved at $200^{\circ} \mathrm{C}$ then the can is closed and extruded at $200-250^{\circ} \mathrm{C}$ through a conical die with ram speed from 0.4 to 2.0 $\mathrm{mm} / \mathrm{s}$ and an extrusion ratio of $22: 1$. The microstructure of the powder particle is investigated by optical micrography, SEM and TEM. The microstructure of the consolidated alloy is examined by SEM and TEM. Phase determination is achieved through X-ray diffraction and electron diffraction. The tensile samples ( $4 \mathrm{~mm}$ in diameter and $16 \mathrm{~mm}$ in gauge length) machined in the bars, are deformed under a strain rate of $5.2 \times 10^{-4} \mathrm{~s}^{-1}$. Complementary information are derived from Vickers hardness measurements with $100 \mathrm{~g}$ load applied for 20 seconds. 


\section{RESULTS AND DISCUSSION}

Microstructure

The spherical powder particles (figure 1), sometimes exhibit a faceted surface (figure 2). The facet has a size ranging from 5 to $10 \mu \mathrm{m}$, and corresponds to the metallurgical grain size. Because the binary alloys $(\mathrm{Mg}-\mathrm{Zn})$ does not show such facets, an anisotropy of surface energy must be induced by the aluminium. Observations of particles sections shows a dual microstructure, cellular-dendritic (figure 3), independent of the aluminium content. The size of the dendrites varies from 7 to $10 \mu \mathrm{m}$ with an interdendritic spacing of about $0.25 \mu \mathrm{m}$. In the powder particles, only two phases are detected by X-ray diffraction, the $\mathrm{Mg}_{17} \mathrm{Al}_{12}$ precipitate and the $\mathrm{Mg}$ matrix. We have no evidence of a binary $\mathrm{Mg}-\mathrm{Zn}$ or ternary $\mathrm{Mg}-\mathrm{Al}-\mathrm{Zn}$ precipitates.

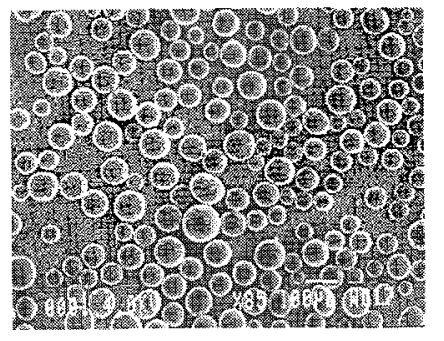

Figure 1 - SEM micrograph. General view.

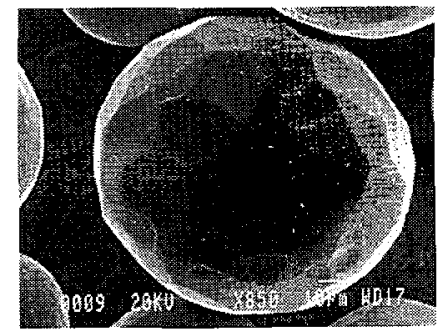

Figure 2 - SEM micrograph. As Figure 3 - SEM micrograph. As solidified powder particle. Faceted particle.

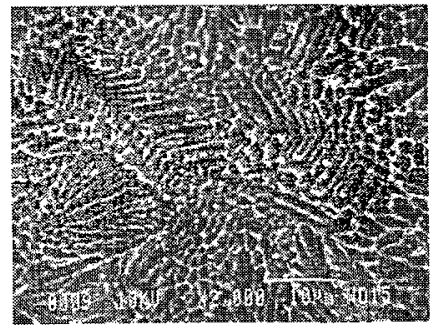

solidified powder particle. Dual dendritic-cellular microstructure.

After consolidation, only the previous phases were still detected. SEM examination shows swelling elongated particles (figure 4). The size of the grain observed by TEM is about $0.2 \mu \mathrm{m}$, relatively free of dislocation, showing a well recristallized structure (figure 5). Two types of precipitate are observed, the first one, intra-granular is spherical with a size of $20 \mathrm{~nm}$, the latter is intergranular with a size varying from 0.1 to $0.2 \mu \mathrm{m}$. (figure 6). Both are indexed as $\mathrm{Mg}_{17} \mathrm{Al}_{12}$. EDX spectroscopy shows that the zinc can enter the matrix and the precipitate $\mathrm{Mg}_{17} \mathrm{Al}_{12}$ as well.

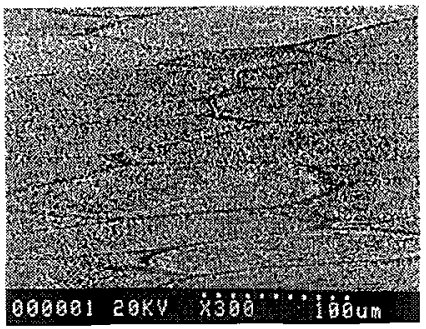

Figure 4 - SEM micrograph. As extruded condition. Longitudinal section.

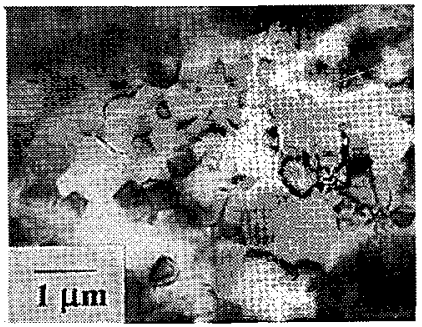

Figure 5 - TEM micrograph. As extruded condition. Transversal section. General view showing the grain size and precipitate

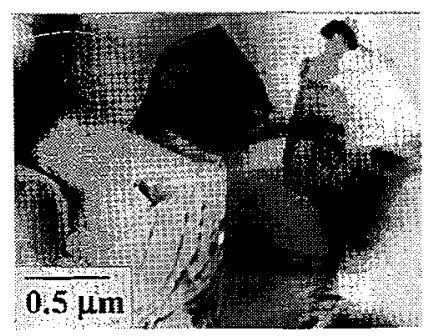

Figure 6 - TEM micrograph. As extruded condition. Transversal section. Dislocation interacting with an $\mathrm{Mg}_{17} \mathrm{Al}_{12}$ precipitate

\section{Physical properties}

Density.

Samples of each composition were prepared by classical ingot route to be used as a reference for porosity measurement. The maximum difference measured is about $0.2 \%$ which means that porosity can not be detected by a density method and that densification has been completely realized during the extrusion. The density of the alloys varies linearly with the aluminium content from $1.845 \mathrm{~g} . \mathrm{cm}^{-3} \mathrm{for} \mathrm{Mg-}$ $1 \mathrm{Zn}-8 \mathrm{Al}$ to $2.034 \mathrm{~g} \cdot \mathrm{cm}^{-3}$ for $\mathrm{Mg}-3 \mathrm{Zn}-20 \mathrm{Al}$ (graph 1). These values compare quite well with those

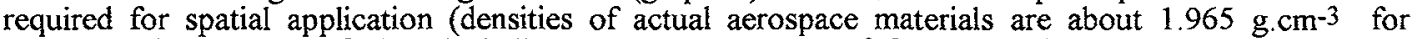
fiberglass glass, $2.5 \mathrm{~g} \cdot \mathrm{cm}^{-3}$ for Al-Li alloys and about $4.45 \mathrm{~g} . \mathrm{cm}^{-3}$ for Ti alloys) [4].

Micro hardness

After extrusion we observe an important increase of $7 \mathrm{kgf} \cdot \mathrm{mm}^{-2}$ per $\mathrm{Al}$ at $\%$ in the range 8 to $20 \%$. The microhardness of the alloys at 3 at $\% \mathrm{Zn}$ is higher of 10 at $20 \mathrm{kgf} \cdot \mathrm{mm}^{-2}$ than the alloys at 1 at $\% \mathrm{Zn}$ (graph 1) 


\section{Tensile properties}

Because of the observed recristallized microstructure, we conclude that no supersaturation is left after consolidation. In order to limit the embrittling character of a high $\mathrm{Mg}_{17} \mathrm{Al}_{12}$ fraction, the alloys are solution treated during 1 hour at $300^{\circ} \mathrm{C}$, then water quenched. We assume that $\mathrm{Mg}_{17} \mathrm{Al}_{12}$ dissolution occurs without a sensitive grain growth. Ageing treatments at $150^{\circ} \mathrm{C}$ are carried out in argon furnaces and terminate by a water quench. Vickers microhardness are periodically measured until 182 hours. This way, the maximum hardness is reached after 8 hours at $150^{\circ} \mathrm{C}$. The tensile samples are aged until the maximum hardness is reached, then tested at room temperature (graph 2). The result on the test performed on conventional sample of the same composition is summarized in the table below.

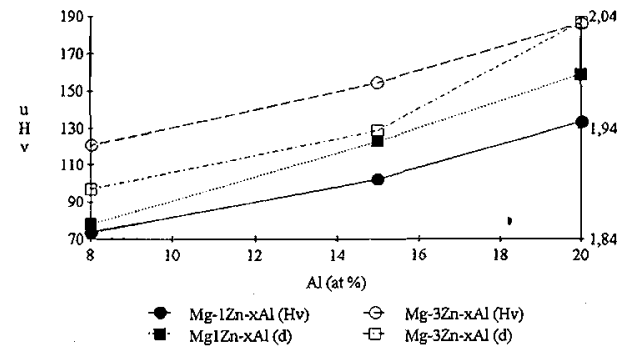

graph 1 - Density (g.cm-3) and microhardness versus $\mathrm{Al}$ content.

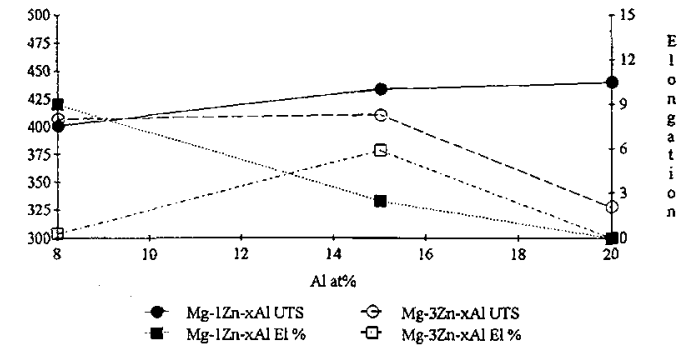

graph 2 - Room temperature UTS (MPa) and elongation versus $\mathrm{Al}$ content.

\begin{tabular}{|c|c|c|c|}
\hline Composition & YS (MPa) & UTS (MPa) & $\varepsilon(\%)$ \\
\hline Mg-1Zn-8Al & 218 & 308 & 8.52 \\
Mg-1Zn-15Al & 320 & 349 & 0.35 \\
Mg-1Zn-20Al & 351 & 351 & 0.09 \\
\hline Mg-3Zn-8A1 & 295 & 432 & 9 \\
Mg-3Zn-15Al & 345 & 365 & 0.275 \\
Mg-3Zn-20Al & 323 & 323 & 0 \\
\hline
\end{tabular}

Mechanical properties of conventional alloys.

\section{Discussion}

An addition of $2 \%$ of $\mathrm{Zn}$ results in a loss of tensile properties. While there is no evidence of GP zones, zinc must be either in solid solution in the matrix, or in substitution in the $\mathrm{Mg}_{17} \mathrm{Al}_{12}$ precipitate. $\mathrm{X}$-ray parameter phase study is on the way to determine the among of zinc dissolved in each phase and the influence of rapid solidification on this dissolution.

The addition of aluminium increases the UTS, except for the alloy $\mathrm{Mg}-3 \mathrm{Zn}-20 \mathrm{Al}$, which exhibits premature failure. The high $\mathrm{Al}$ contents alloys have no ductility, due to the large volume fraction of precipitates. Compared to the results of the conventional samples, the UTS of R/S alloys is between 50 to $100 \mathrm{MPa}$ higher, except on $\mathrm{Mg}-3 \mathrm{Zn}-20 \mathrm{Al}$ and $\mathrm{Mg}-1 \mathrm{Zn}-8 \mathrm{Al}$. An important fact is that $\mathrm{R} / \mathrm{S}$ alloys $\mathrm{Mg}-$ $x Z n-15 \mathrm{Al}$ have some ductility while conventional have not, probably due to the finest grain size of the former.

\section{Corrosion behaviour.}

Samples of each composition, rapidly solidified or not, have been tested by the weight loss method during one week in 3\% salt water. The results are listed in the graph $3:$ all the rapidly solidified alloys have a higher corrosion resistance because of the finest microstructure. This is underlined by the corrosion aspect of a $\mathrm{Mg}-1 \mathrm{Zn}-15 \mathrm{Al}$ alloy surface after 12 days exposure in $3 \%$ salt water (rapid solidification (figure 7) and classic solidification (figure 8)). 


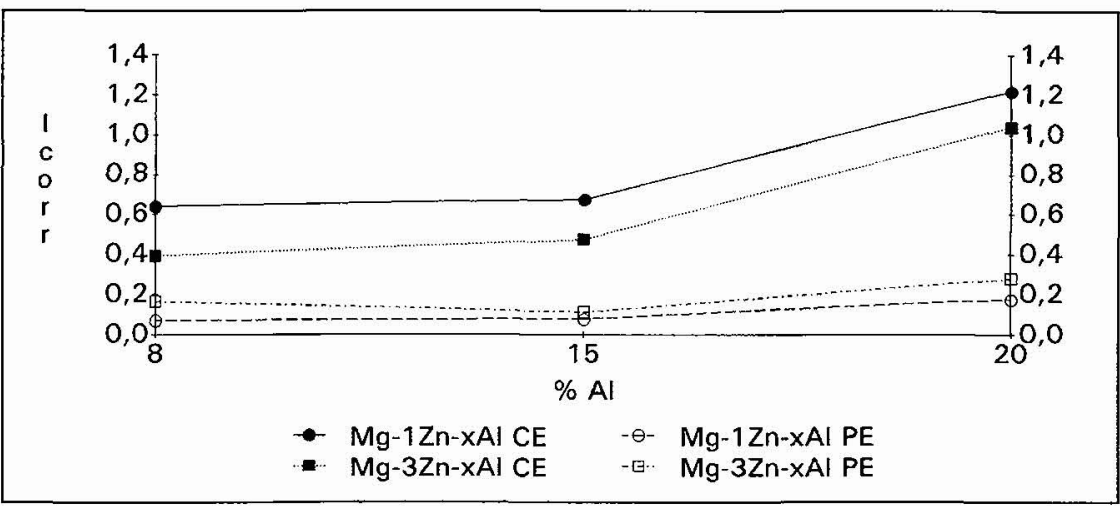

graph 3 - Evolution of corrosion rate (cm/year) in 3\% salt water versus $\mathrm{Al}$ content.
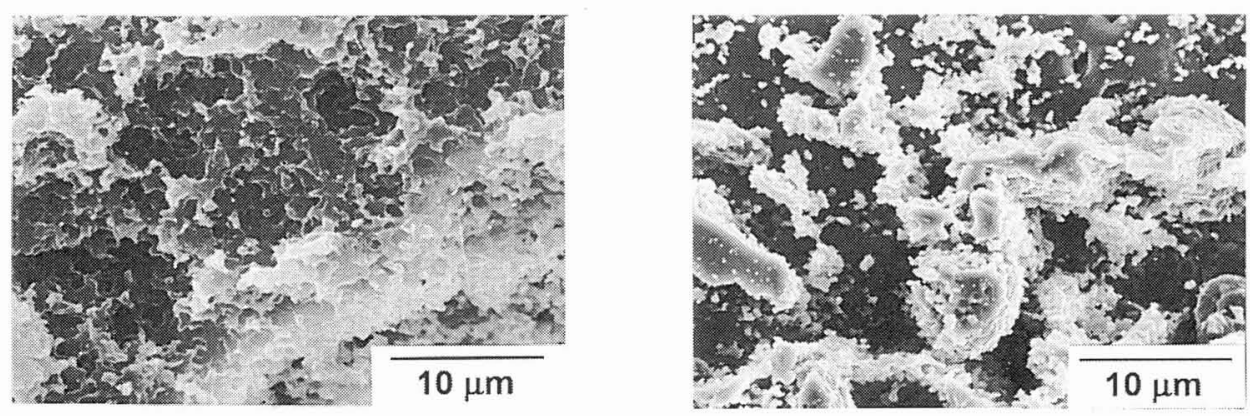

Figure 7. - SEM micrograph. Surface of $\mathrm{R} / \mathrm{S} \mathrm{Mg}-$ $1 \mathrm{Zn}-15 \mathrm{Al}$ after 12 days in salt water.

Figure 8. - SEM micrograph. Surface of $\mathrm{I} / \mathrm{M}$ Mg$1 \mathrm{Zn}-15 \mathrm{Al}$ after 12 days in salt water.

\section{CONCLUSIONS}

The alloys $\mathrm{Mg}-1 \mathrm{Zn}-15 \mathrm{Al}$ and $\mathrm{Mg}-3 \mathrm{Zn}-15 \mathrm{Al}$ exhibit interesting mechanical and corrosion properties due to the fine grain size and the high volumic fraction of fine precipitate induced by rapid solidification. Role of zinc is not obvious in these properties, particularly if we notice that higher is the zinc content, better is the ductility. On one hand, appropriate extrusion conditions and solution treatment must be determined in order to increase the ductility of the higher Al content alloys, on the other hand, a complete electrochemical study must be carried out to determine the influence of the microstructure obtained by rapid solidification on the corrosion resistance.

\section{REFERENCES}

1) GALLOT J., Ph D Thesis, Université de ROUEN, FRANCE, (1966)

2) NUSSBAUM G., SAINFORT P., REGAZZONI G., GJESTLAND H., Script. Met. 23, (1989), 1079

3)ARCADE P., CHAMPIER G., MICHOT G., European Patent N $9 / 40 / 246,3,1991$

4) LEWIS R.E., JOSHI A., JONES H., Processing of Structural Metals by Rapid Solidification, ed F.H. Froes and S.J. Savage, (1986), 367 